Genij Ortopedii. 2021. Vol. 27, no. 5. P. 527-531.

Original article

https://doi.org/10.18019/1028-4427-2021-27-5-527-531

\title{
Evaluation of the quality of life dynamics by methods of survival analysis in patients with hip joint ar-throplasty
}

\author{
A.N. Tkachenko ${ }^{1,2 \bowtie}$, A.A. Korneenkov ${ }^{3}$, Yu.L. Dorofeev², D.Sh. Mansurov ${ }^{1}$, A.A. Khromov ${ }^{1}$, V.M. Khaidarov ${ }^{1}$, \\ A.A. Vorokov', B.G. Aliev ${ }^{1}$
}

${ }^{1}$ North-Western State Medical University named after I.I. Mechnikov, Saint Petersburg, Russian Federation

${ }^{2}$ Scandinavia Ava-Peter, Clinic, St. Petersburg, Russian Federation

${ }^{3}$ Kirov Military Medical Academy, Saint Petersburg, Russian Federation

Corresponding author: Aleksandr N.Tkachenko, altkachenko@mail.ru

\begin{abstract}
Introduction The study deals with the approaches to the analysis of the dynamics in the course of a long-term postoperative period in patients who underwent hip arthroplasty. Aim To feature the variants in the course of a long-term postoperative period in patients who underwent arthroplasty of the hip joint. Materials and methods 806 patients (age range, 9 to 88 years) suffering from osteoarthritis underwent primary total hip arthroplasty (THA). Statistical analysis was carried out using the R programming language, freely available at https://cran.r-project.org. The probability of maintaining satisfactory quality of life $(\mathrm{QoL})$ at a certain time of observation $\mathrm{t}$ (year of observation) was assessed with the Kaplan-Meier method. To compare the likelihood of maintaining a satisfactory QoL level throughout the observation period in several groups (for example, patients of different sexes), the logrank test was used. Results By year 6 of follow-up, the following tendency emerges regarding the age of the patients. The indicators are the best in young patients (up to 44 years old), where the probability of maintaining a satisfactory QoL evaluation was $0.92(0.84 ; 0.96)$. A somewhat lower values were observed in the patients of the middle age group (from 45 to 64 years old) - $0.87(0.78 ; 0.92)$. Excellent and good QoL was found in patients aged 65 and older, $0.83(0.76 ; 0.88)$. Discussion Survival analysis methods have been used for the first time in traumatology and orthopedics. Previous researchers assessed the long-term results of the quality of specialized traumatological and orthopedic care without considering censored observations. Thus, the coverage of the investigated clinical observations averaged $80-85 \%$. Information about $10-15 \%$ of cases was excluded from the studies. The proposed method of analysis provides information about all patients. Conclusions Five years following THA, an excellent and good quality of life could be expected in $85 \%$ of patients. Satisfactory and poor levels are observed in $15 \%$ of patients. At 5-year follow-up after THA, the quality of life is worse in older female groups with severe concomitant pathology; however, there are no statistically significant differences. This is a tendency, and requires further study. Keywords: osteoarthritis, hip arthroplasty, quality of life, survival analysis, Kaplan-Meier method
\end{abstract}

For citation: Tkachenko A.N., Korneenkov A.A., Dorofeev Yu.L., Mansurov D.Sh., Khromov A.A., Khaidarov V.M., Vorokov A.A., Aliev B.G. Evaluation of the quality of life dynamics by methods of survival analysis in patients with hip joint ar-throplasty. Genij Ortopedii, 2021, vol. 27, no 5, pp. 527531. https://doi.org/10.18019/1028-4427-2021-27-5-527-531

\section{INTRODUCTION}

Analysis of the dynamics in the course of the postoperative period after hip arthroplasty in order to predict long-term results is one of the main objectives of clinical trials $[1,2]$. In general, the survival of implants, ac-cording to differentauthors, is 10-15 years, afterwhich a partial or complete exchange is required. Usually, the event that is of interest in this case is the manifestation of one or another symptom that worsens the everyday life of the patient who underwent THA and affects both the functional results and the patient's quality of life. There are situations when communication with the patient is lost, or there is not enough observation time to register the outcome of interest. These are the so-called censored cases, the observation time of which must also be taken into account to calculate the probability of the occurrence of the event of interest during the period of a clinical study. In the practice of an orthopedic traumatologist, such cases are not uncommon. During this entire observation period, the patient's quality of life decreases [3-7]. To process information from censored cases (when communication with the patient is lost), statistical methods for survival analysis have been developed [8]. However, their use in relation to the description of the dynamics in the course of the postopera-tive period in traumatology and orthopedics has not been widespread.

Purpose The study analyzed the quality of life dynamics in the postoperative period in the short and medi-um perspective to demonstrate the solutions on several variants in the course of the postoperative period in patients who underwent hip arthroplasty due to osteoarthritis. The prognosis of the quality of life was deter-mined in dependence on the patient's age, gender, body mass index, concomitant pathology. Long-term results of hip arthroplasty in patients of different groups were compared. A model of the probability of the course of the postoperative period was constructed with the statistical software environment $\mathrm{R}$.

\section{MATERIAL AND METHODS}

The clinic for traumatology and orthopedics of the Mechnikov State Medical University (hereinafter re-ferred to as the clinic) performed primary total hip arthroplasty due to osteoarthritis in 806 patients aged 19 to 88 years from 2014 to 2018 (inclusive). Inclusion criteria were primary total hip arthroplasty for

(c) Tkachenko A.N., Korneenkov A.A., Dorofeev Yu.L., Mansurov D.Sh., Khromov A.A., Khaidarov V.M., Vorokov A.A., Aliev B.G., 2021 
diagnosed hip joint osteoarthritis. The exclusion criteria were deaths during or immediately after the surgery. Mortality in the early postoperative period was $0.4 \%$ ( 3 cases out of 806). All 803 patients who underwent THA and were discharged from the clinic were included into the study. Statistical data processing and graphic creation were carried out using the R software language freely available at https://cran.r-project.org [1]. Primary medical documentation (medical records, outpatient records) was used for studying data on patients who underwent hip joint arthroplasty. The information was transferred to the database. To complete a full database, an intermediate document was created, a formalized chart. It included 47 items of both retrospective and pro-spective stages of the study. To solve the problems presented in this article, the baseline data included records of patients who were followed for 6 years after surgery. There were 3 types of variables in the dataset: 1) the dependent variable "time" is the time until the appearance of an unsatisfactory event in the quality of life or reaching the end of observation; 2) the censoring variable "status", which reflects the status at the end of the 6-year follow-up (0 - an unsatisfactory QoL score was not noted or the patient dropped out of the study, 1 - an unsatisfactory QoL score was recorded during the observation period); 3 ) three explanatory variables (in R scales: factor variables), whose impact we wished to assess: SEX - patient gender (male "mal", female "fem", riskASA - shortened ASA system (2 levels: "below average" and " above average "), AGECAT - age catego-ry ("adult"- from 19 to 44 years old; "middleaged"- from 45 to 64 years old; "elderly" - 65 years of age or more). For observation, the nonparametric Kaplan-Meier method of analysis was used; to compare the impact of factors on maintaining a satisfactory quality of life (QoL) assessment, the logrank test was used $[1,9,10]$.

The evaluation of the probability of maintaining a satisfactory assessment of QoL (or in terms of the method used - "survival") up to a certain point of observation $\mathrm{t}$ (year of observation) was carried out using the KaplanMeier method. In the course of this procedure, the survival function $\mathrm{S}(\mathrm{t})$ was determined - the proba-bility that a satisfactory assessment of the quality of life will be observed at time point $t$, and a survival curve was constructed, according to which it is possible to predict the probability of maintaining a satisfactory as-sessment of the quality of life at a certain point in time [8]. To compare the likelihood of maintaining a satis-factory QoL score throughout the observation period in several groups (for example, patients of different sex-es), the logrank test was used [10].

The studies were approved by the ethical committee of the North-Western Mechnikov State Medical University and were carried out in accordance with the ethical standards set out in the Declaration of Helsinki. Informed consent to conduct the study was obtained from all patients.

\section{RESULTS}

It is possible to calculate an estimate of the probability of the occurrence of an event of interest at any time of observation using the curves of the probability of survival or using special functions for any year of obser-vation. For example, at the beginning of the 6th year of observation, the estimate of the probability of main-taining a satisfactory QoL with a $95 \%$ confidence interval was $0.863(0.82 ; 0.897)$. Figure 1 shows the curve for the likelihood of maintaining a satisfactory QoL estimate with a $95 \%$ confidence interval.

In order to search for the influence of some parameters on the deterioration of the quality of life, such fac-tors as age, gender, body mass index, anesthetic risk were analyzed separately as an integral indicator of the severity of concomitant diseases.

Figure 2 shows the risk curves of maintaining an excellent and good quality of life in patients undergoing THA, depending on gender.

As the result of the log-rank test showed, the test statistics $(Z=-0.26916)$ and the level of significance $p$ ( $\mathrm{p}$-value $=0.7888)$ indicate the absence of statistically significant differences in the survival curves (preservation) of a satisfactory assessment of QoL between groups of patients of different sex. The log-rank test is used only to test for the statistical significance of a difference and cannot provide an estimate of the magnitude of the difference between groups. The graph in Figure 2 illustrates the differences between the two survival curves for satisfactory QoL after surgery depending on gender. As follows from the data presented in the figure, before the 5th year of follow-up, the quality of life for both men and women does not differ. However, in the fifth, and especially by the 6th year of followup, a tendency appears, indicating that the probability of maintaining a satisfactory assessment of the QoL of female patients decreases to $0.84(0.78 ; 0.89)$, in contrast to males $-0.89(0.84 ; 0.92)$.

As for the age of the patients (Fig. 3), the following tendency is observed on the 6th year of follow-up: the best results are in young patients (up to 44 years old) with the probability of maintaining a satisfactory as-sessment $0.92(0.84 ; 0.96)$. Somewhat lower it was in patients of the middle age group (from 45 to 64 years old inclusive) $0.87(0.78 ; 0.92)$. Excellent and good quality of life in patients aged 65 and over $-0.83(0.76 ; 0.88)$.

The log-rank test indicates that there are no statistically significant differences in survival curves between these age groups (Chi-square $=2.9184$ and $\mathrm{p}$-value $=0.2349$ ). However, the tendency is traced clearly, which requires further study of this issue.

As follows from the data presented in Figure 4, the long-term results of hip arthroplasty in patients with ASA grade I-II (less pronounced severity of concomitant pathology) is somewhat better. The probability of an excellent and good quality of life by the end of the 5 th year of observation is 0.89 ( $0.81 ; 0.94)$. Among the clinical cases with ASA grades III-IV this value is slightly lower, $0.86(0.81 ; 0.89)$. 


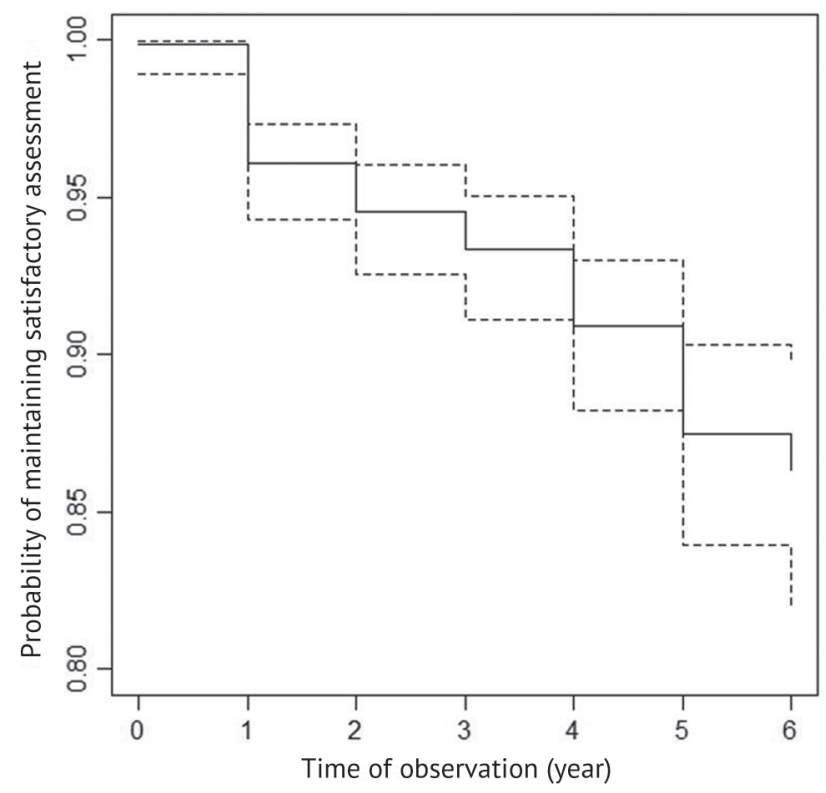

Fig. 1 Curve of change in the risk assessment of maintaining excellent and good quality of life results with a $95 \%$ confidence inter-val

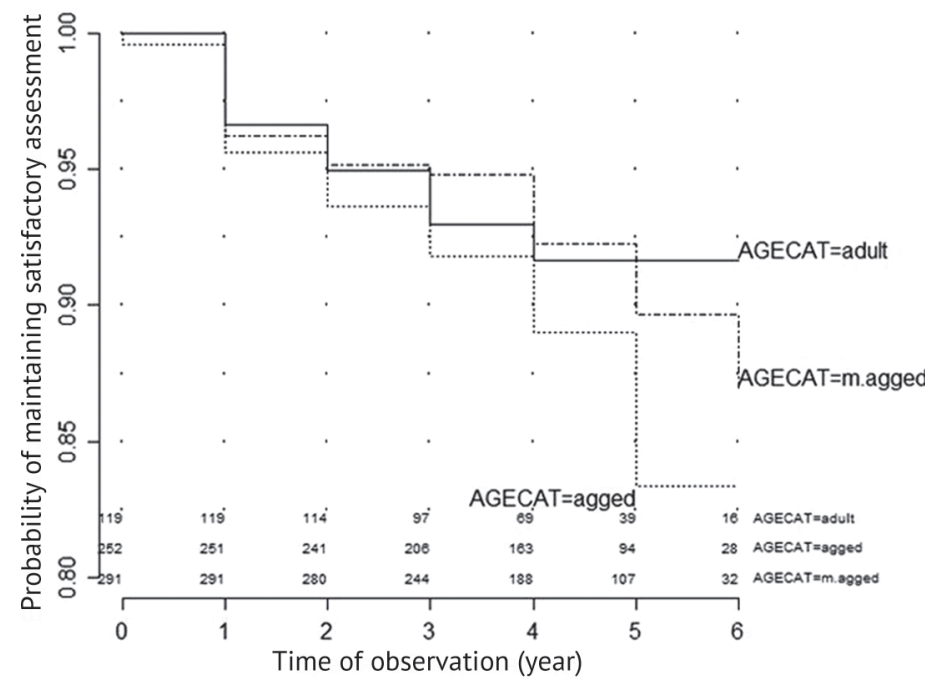

Fig. 3 Curve of change in the risk assessment of maintaining excellent and good quality of life results depending on the age of pa-tients with a $95 \%$ confidence interval (adult - from 19 to 44 years; $m$. aged - from 45 to 64 years; aged -65 and older)

The log-rank test indicates the absence of significant differences in survival curves between groups of pa-tients with different ASA $(Z=0.94633$ and $\mathrm{p}$-value $=0.3435)$. As in all previous observations,

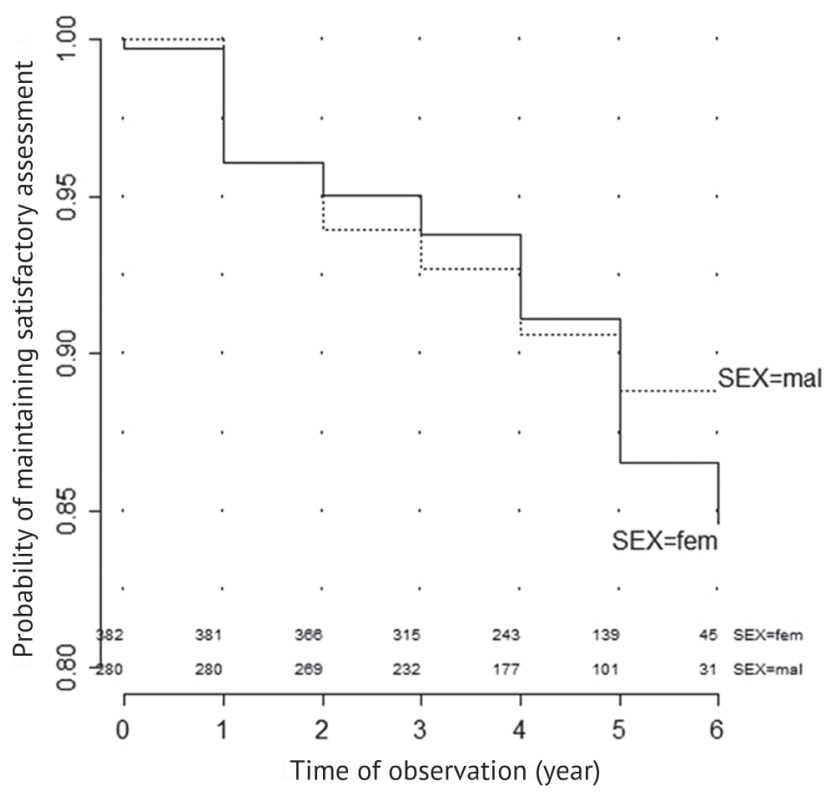

Fig. 2 Curve of change in the assessment of the risk of maintaining excellent and good quality of life results depending on gender with a $95 \%$ confidence interval (fem - women; mal - men)

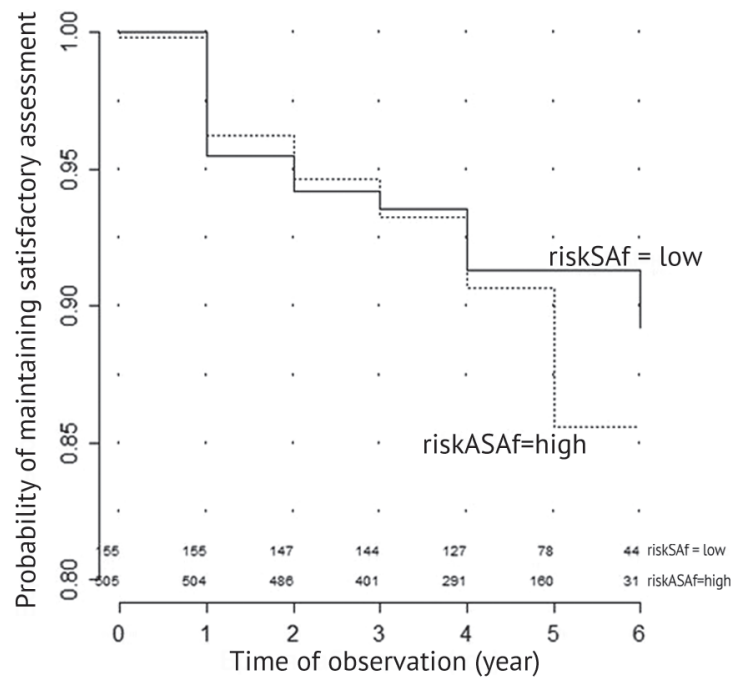

Fig. 4 Curve of change in the risk assessment of maintaining excellent and good quality of life results depending on the anesthesia risk with a $95 \%$ confidence interval (risk SA f $=$ low risk of anesthesia ASA grade I-II; risk ASA $\mathrm{f}=$ high - risk of anesthesia in ASA grade III-IV)

these results cannot be considered significant from the point of view of statistics. This is a tendency, which undoubtedly requires further study of the THA results in the long term of 10 and 15 years.

\section{DISCUSSION}

In most publications in the field of traumatology and orthopedics, the reliability of the obtained results is assessed using statistical data processing with software packages (mainly STATISTICA 10, etc.) [11-14]. As a rule, the correspondence of the studied parameters of the indicators to the law of normal distribution has been studied. The parametric methods have been usually used to determine the arithmetic mean (M) and the mean error (m). The reliability of quantitative normally distributed factors is characterized by the Student's t-test. If the analyzed parameters do not correspond to the normal distribution law, nonparametric methods are used: the Mann-Whitney U-test for comparing the study and control groups for one indicator, Wilcoxon matched pairs test for comparing the dynamics of changes in the indicator in the experimental and control groups, the median test and the Kruskal-Wallis test if three or more indicators are to be compared (as in the intergroup comparison). However, the proposed method of statistical analysis is possible to use considering the data on all patients. Data on the patients with whom communication was lost at some point in time are not taken into account. 
The survival analysis methods have been used for the first time in the domestic traumatology and orthopedics $[4,15]$. Previous researchers assessed the long-term results of the quality of specialized traumatological and orthopedic care without considering censored observations. The coverage of the investigated clinical ob-servations averaged 80-85\%. Information about $10-15 \%$ of cases was excluded from the studies due to una-vailable treatment results as the communication with those patients was lost. Similar information on traumato-logical and orthopedic patients has been presented in foreign works [16-20].
Patient's quality of life after hip arthroplasty was determined by both subjective assessments and objective measurements and was recorded in the specified follow-up time point. The study, using the example of ana-lyzing the dynamics of the quality of life in the postoperative period in the short and medium terms, enables to demonstrate the solution of several variants of the postoperative period course in patients who underwent hip arthroplasty due to osteoarthritis. The prognosis of the quality of life was assessed by patient's age, gender, body mass index, and concomitant pathology.

\section{CONCLUSIONS}

The method of survival analysis for the study of longterm results of treatment is of interest primarily due to the high probability of loosing communication with the patient in the long term after the operation as it al-lows the use of censored observations. Based on the presented example and interpreting the results obtained in terms that are more understandable for practitioners, we can draw the following conclusions: a) $85 \%$ of patients are expected to have excellent and good quality of at 5 years following THA due to osteoarthritis. Satisfactory and unsatisfactory quality are found in $15 \%$ of patients; b) quality of life 5 years after hip arthro-plasty is somewhat worse in older female patients with severe concomitant pathology but these differences cannot be considered statistically significant $(p>0.05)$. This is a tendency that requires further study.

\section{REFERENCES}

1. Korneenkov A.A., Fanta I.V., Viazemskaia E.E. Otsenka dinamiki simptomov bolezni metodami analiza vyzhivaemosti [Evaluation of the dynamics of disease symptoms by the methods of survivability analysis]. Rossiiskaia Otorinolaringologiia, 2019, vol. 18, no. 4, pp. 8-14. (in Russian). Available at: https://doi.org/10.18692/1810-4800-2019-4-8-14.

2. Korneenkov A.A., Fanta I.V. Otsenka razmera effekta klinicheskogo vozdeistviia v otorinolaringologii [Evaluation of the size of clinical impact in otorhinolaryngology]. Rossiiskaia Otorinolaringologiia, 2020, vol. 19, no. 2, pp. 42-50. (in Russian). Available at: https://doi.org/10.18692/18104800-2020-2-42-50.

3. Goriannaia N.A., Ishekova N.I., Popov V.V., Bondarenko E.G. Izmenenie kachestva zhizni patsientov posle endoprotezirovaniia tazobedrennogo sustava na pervom etape reabilitatsii [Change of the patient quality of life after the hip arthroplasty at the first stage of rehabilitation]. Ekologiia Cheloveka, 2017, no. 1, pp. 41-44. (in Russian)

4. Golubev G.Sh., Kabanov V.N., Golubev V.G. Otsenka otdalennykh rezultatov endoprotezirovaniia tazobedrennogo sustava, vypolnennogo iz raznykh khirurgicheskikh dostupov [Evaluation of long-term results of the hip arthroplasty, performed from different surgical approaches]. Vestnik Travmatologii i Ortopedii im. N.N. Priorova, 2008, no. 2, pp. 48-52. (in Russian)

5. Rasouli M.R., Restrepo C., Maltenfort M.G., Purtill J.J., Parvizi J. Risk factors for surgical site infection following total joint arthroplasty. J. Bone Joint Surg. Am., 2014, vol. 96, no. 18, pp. e158. DOI: 10.2106/JBJS.M.01363.

6. Daniliak V.V., Kliuchevskii V.V., Molodov M.A., Goriunov E.V., Marchenkova K.V. Dolgosrochnye rezultaty totalnoi artroplastiki tazobedrennogo sustava s ispolzovaniem atsetabuliarnogo komponenta RM-classic [Long-term results of the hip total arthroplasty using RM-classic acetabular component]. Travmatologiia i Ortopediia Rossii, 2019. vol. 25, no. 3, pp. 25-33. (in Russian) DOI: 10.21823/2311-2905-2019-25-3-25-33.

7. Jawad Z., Nemes S., Bülow E., Rogmark C., Cnudde P. Multi-state analysis of hemi- and total hip arthroplasty for hip fractures in the Swedish population - Results from a Swedish national database study of 38,912 patients. Injury, 2019, vol. 50, no. 2, pp. 272-277. DOI: 10.1016/j. injury.2018.12.022.

8. Kotz S., Balakrishnan N., Read B.C., Vidakovic B., editors. Encyclopedia of Statistical Sciences. 2nd Edition. Wiley-Interscience. 2005. Vol. 6. $680 \mathrm{p}$.

9. Kaplan E.L. Meier P. Nonparametric Estimation from Incomplete Observations. Journal of American Statistical Association, 1958, vol. 53, pp. 457481. DOI: 10.1080/01621459.1958.10501452.

10. Bland J.M., Altman D.G. The logrank test. BMJ, 2004, vol. 328, no. 7447, pp. 1073. DOI: 10.1136/bmj.328.7447.1073.

11. Githens M., Haller J., Agel J., Firoozabadi R. Does concurrent tibial intramedullary nailing and fibular fixation increase rates of tibial nonunion? A matched cohort study. J. Orthop. Trauma, 2017, vol. 31, no. 6, pp. 316-320. DOI: 10.1097/BOT.0000000000000832.

12. Raith E.P., Udy A.A., Bailey M., McGloughlin S., MacIsaac C., Bellomo R., Pilcher D.V.; Australian and New Zealand Intensive Care Society (ANZICS) Centre for Outcomes and Resource Evaluation (CORE). Prognostic accuracy of the SOFA Score, SIRS Criteria, and qSOFA Score for in-Hospital Mortality among adults with suspected infection admitted to the intensive care unit. JAMA, 2017, vol. 317, no. 3, pp. 290-300. DOI: 10.1001/jama.2016.20328.

13. Scharfenberger A.V., Alabassi K., Smith S., Weber D., Dulai S.K., Bergman J.W., Beaupre L.A. Primary wound closure after open fracture: a prospective cohort study examining nonunion and deep infection. J. Orthop. Trauma, 2017, vol. 31, no. 3, pp. 121-126. DOI: 10.1097/ BOT.0000000000000751.

14. Pedersen A.B., Mehnert F., Havelin L.I., Furnes O., Herberts P., Kärrholm J., Garellick G., Mäkela K., Eskelinen A., Overgaard S. Association between fixation technique and revision risk in total hip arthroplasty patients younger than 55 years of age. Results from the Nordic Arthroplasty Register Association. Osteoarthritis Cartilage, 2014, vol. 22, no. 5, pp. 659-667. DOI: 10.1016/j.joca.2014.03.005.

15. Tkachenko A.N., Gaikovaia L.B., Ekhsan-ul-khak, Korneenkov A.A., Kushnirchuk I.I., Mansurov D.Sh., Ermakov A.I. Vozmozhnosti prognoza mestnykh infektsionnykh oslozhnenii pri metalloosteosinteze dlinnykh kostei konechnostei [Possibilities for predicting local infectious complications in metal osteosynthesis of long limb bones]. Novosti Khirurgii, 2018, vol. 26, no. 6, pp. 697-706. (in Russian)

16. Yasunaga Y., Ochi M., Yamasaki T., Shoji T., Izumi S. Rotational acetabular osteotomy for pre- and early osteoarthritis secondary to dysplasia provides durable results at 20 years. Clin. Orthop. Relat. Res., 2016, vol. 474, no. 10, pp. 2145-2153. DOI: 10.1007/s11999-016-4854-8.

17. Claessen F.M., Braun Y., van Leeuwen W.F., Dyer G.S., van den Bekerom M.P., Ring D. What factors are associated with a surgical site infection after operative treatment of an elbow fracture? Clin. Orthop. Relat. Res., 2016, vol. 474, no. 2, pp. 562-570. DOI: 10.1007/s11999-015-4523-3.

18. Romanò C.L., Morelli I., Romanò D., Meani E., Drago L. ICS classification system of infected osteosynthesis: Long-term results. Injury, 2018, vol. 49, no. 3, pp. 564-569. DOI: 10.1016/j.injury.2018.01.002.

19. Huddleston J.I., Harris A.H., Atienza C.A., Woolson S.T. Hylamer vs conventional polyethylene in primary total hip arthroplasty: a long-term case- 
control study of wear rates and osteolysis. J. Arthroplasty, 2010, vol. 25, no. 2, pp. 203-207. DOI: 10.1016/j.arth.2009.02.006.

20. Dielwart C., Harmer L., Thompson J., Seymour R.B., Karunakar M.A. Management of closed diaphyseal humerus fractures in patients with injury severity score $\geqslant 17$. J. Orthop. Trauma, 2017, vol. 31, no. 4, pp. 220-224. DOI: 10.1097/BOT.0000000000000768.

The article was submitted 26.05.2021; approved after reviewing 01.06.2021; accepted for publication 23.08.2021.

\section{Information about the authors:}

1. Aleksandr N. Tkachenko - Doctor of Medical Sciences, Professor, altkachenko@mail.ru;

2. Alexey A. Korneenkov - Doctor of Medical Sciences, Professor, korneyenkov@gmail.com;

3. Yuri L. Dorofeev-Candidate of Medical Sciences, dorofeev76@list.ru;

4. Djalolidin Sh. Mansurov - Candidate of Medical Sciences, jalolmedic511@gmail.com;

5. Alexander A. Khromov,-Candidate of Medical Sciences, khromov_alex@mail.ru;

6. Valeriy M. Khaidarov - Candidate of Medical Sciences, drxaydarov@mail.ru;

7. Alimbek A. Vorokov - M.D., alimbekvor@icloud.com;

8. Bakhtiyar G. Aliev - M.D., dr.aliyev@mail.ru.

Conflict of interests The authors declare that they have no conflicts of interest.

Source of funding The study was conducted without sponsorship. 